\title{
NARRATIVE REVIEW: IMPLEMENTASI DISTRIBUSI OBAT YANG BAIK DI PEDAGANG BESAR FARMASI
}

\section{Narrative review: Implementation of Good Distribution Practice in Pharmaceutical Wholesalers}

\section{Mustaqimah ${ }^{\text {* }}$ \\ Rina Saputri ${ }^{2}$ \\ Ali Rakhman Hakim ${ }^{3}$ \\ *IUniversitas Sari Mulia, Banjarmasin, Kalimantan Selatan, Indonesia \\ 2Universitas Sari Mulia, Banjarmasin, Kalimantan Selatan, Indonesia \\ 3Universitas Sari Mulia, Banjarmasin, Kalimantan Selatan, Indonesia \\ *email: mustaqimah@unism.ac.id}

\begin{abstract}
Abstrak
Distribusi sediaan farmasi dari industri farmasi sebelum sampai ke tempat pelayanan kefarmasian harus melalui PBF. Cara distribusi obat yang baik merupakan kumpulan metode kerja rutin yang terstandar, yang memastikan bahwa kualitas, keamanan, dan kemanjuran produk farmasi tetap utuh sejak awal hingga akhir masa kadaluwarsa. Cara distribusi obat yang baik harus diimplementasikan oleh semua PBF yang ada di Indonesia agar operasional PBF dapat berjalan efektif dan efisien. Semua pedagang besar farmasi harus memiliki standar operasional prosedur, personalia yang berintegritas, dan sistem pendokumentasian yang baik.
\end{abstract}

\section{Kata Kunci: \\ CDOB \\ PBF}

\begin{abstract}
Distribution of pharmaceutical products from the pharmaceutical industry before reaching the pharmacy service point must be through the wholesale. Good distribution practice methods are a set of standardized routine working methods, which ensure the quality, safety and efficacy of pharmaceutical products remain intact from the very beginning to the end of the expiration period. Good distribution practice methods must be implemented by all wholesale in Indonesia so that wholesale operations can run effectively and efficiently. All pharmaceutical wholesalers must have standard operating procedures, personnel with integrity, and a good documentation system.
\end{abstract} (c) year The Authors. Published by Institute for Research and Community Services Universitas Muhammadiyah Palangkaraya. This is Open Access article under the CC-BY-SA License (http://creativecommons.org/licenses/by-sa/4.0/). DOI: https://doi.org//0.33084/jsm.vxix.xxx.

\section{PENDAHULUAN}

Peredaran sediaan farmasi di Indonesia berada di bawah kontrol Badan Pengawas Obat dan Makanan (BPOM). Badan Pengawas Obat dan Makanan telah mengatur regulasi tentang sediaan farmasi mulai dari produksi hingga akhirnya dapat digunakan oleh masyarakat. Setiap provinsi di Indonesia telah ada BPOM tujuannya agar peredaran sediaan farmasi dapat terjaga kualitas dan keamanannya. Distribusi sediaan farmasi dari industri farmasi sebelum sampai ke tempat pelayanan kefarmasian harus melalui Pedagang Besar Farmasi
(PBF). Pedagang besar farmasi merupakan penyalur sediaan farmasi pasca produksi dan siap didistribusikan ke fasilitas kesehatan seperti apotek atau instalasi farmasi. Pedagang Besar Farmasi merupakan perusahaan berbentuk badan hukum yang memiliki izin untuk melakukan pengadaan, penyimpanan, penyaluran perbekalan farmasi dalam jumlah besar sesuai ketentuan peraturan perundang-undangan yang berlaku.

Pedagang besar farmasi di Indonesia ada yang dimiliki oleh Pemerintah dan ada yang dimiliki oleh swasta. PBF harus bisa menjamin mutu, khasiat, dan keamanan dari sediaan farmasi yang mereka distribusikan. Oleh karena 
itu, diperlukan pengawasan secara komprehensif dari pemerintah dan dapat dimulai dari jaringan distribusi obat berupa PBF sebagai penyalur sediaan farmasi yang legal secara hukum. PBF bertugas untuk menyalurkan obat kepada PBF lain, apotek, puskesmas hingga rumah sakit. Permasalahan yang muncul dalam proses distribusi sediaan farmasi adalah masih sering ditemukan penyebaran sediaan farmasi palsu atau biasa disebut obat palsu dan penjualan sediaan farmasi yang ilegal atau obat tidak berizin. Permasalahan masih banyaknya obat palsu dan obat ilegal yang beredar antara lain disebabkan karena pengawasan kegiatan impor dan ekspor yang masih belum optimal oleh pemerintah serta bahan baku dan alat pembuat sediaan farmasi mudah didapatkan oleh para pembuat obat palsu.

Pada tahun 2020 Badan Pengawas Obat Dan Makanan mengeluarkan peraturan Nomor 6 Tahun 2020 tentang Perubahan Atas Peraturan Badan Pengawas Obat Dan Makanan Nomor 9 Tahun 2019 Tentang Pedoman Teknis Cara Distribusi Obat Yang Baik (CDOB) yang perlu dipatuhi oleh semua PBF sebagai fasilitas distribusi obat di Indonesia (BPOM, 2020). Ketentuan CDOB merupakan panduan standar distribusi sediaan farmasi yang komprehensif yang meliputi aspek pengadaan, penyimpanan, hingga penyaluran ke tempat pelayanan kefarmasian. Setiap PBF harus memiliki apoteker penanggung jawab (APJ) yang bertanggung jawab terhadap proses pengadaan, penyimpanan dan penyaluran obat. Apoteker penanggung jawab harus pernah mengikuti pelatihan CDOB. Penerapan CDOB merupakan standar agar PBF dapat mempertahankan dan memastikan mutu obat yang diterima oleh pasien sama dengan mutu obat yang dikeluarkan oleh industri farmasi. Sebuah PBF dalam menerapkan CDOB juga harus memiliki sistem manajemen yang baik. Sistem manajemen yang baik harus ditunjang dengan adanya standar operasional prosedur (SOP), sumber daya manusia atau personalia yang berintegritas, dan sistem pendokumentasian yang baik.

\section{METODOLOGI}

Metode yang digunakan pada penelitian ini adalah dengan melakukan pencarian artikel ilmiah menggunakan database google dan google scholar. Artikel dicari menggunakan kata kunci CDOB, GDP, PBF, dan SOP. Artikel yang dinilai sesuai akan digunakan sebagai referensi.

\section{HASIL DAN PEMBAHASAN}

Cara distribusi obat yang baik (CDOB) merupakan kumpulan metode kerja rutin yang terstandar, yang memastikan bahwa kualitas, keamanan, dan kemanjuran produk farmasi tetap utuh sejak awal hingga akhir masa kadaluwarsa. Karakteristik dari CDOB yang mencakup semua aspek dapat memberikan banyak peluang untuk efisiensi yang lebih besar dalam operasional PBF. Namun, CDOB yang mencakup semua aspek juga membuatnya rentan terhadap munculnya titik lemah yang dapat memudahkan masuknya produk-produk ilegal (Cvetanovski et al., 2020).

Faktor-faktor yang mempengaruhi peredaran obat yang dipalsukan atau produk ilegal adalah keuntungan ekonomi yang besar, kurangnya peraturan dan undangundang, jalur penyediaan obat yang beragam, sistem keamanan obat yang lemah, dan kesalahpahaman konsumen dan tenaga kesehatan (Jeong \& Ji, 2018). Untuk mencegah distribusi sediaan farmasi berkualitas buruk, maka implementasi CDOB harus berkualitas baik di PBF yang dimiliki oleh pemerintah maupun PBF yang dimiliki oleh swasta (Jeong \& Ji, 20I8; Van Assche et al., 2018).

\section{A. Manajemen dan Personalia}

Sesuai dengan peraturan perundang-undangan PBF wajib memiliki Apoteker sebagai penanggung jawab yang biasa disebut dengan Apoteker Penanggung Jawab (APJ). Sebagai APJ, apoteker harus memiliki kompetensi CDOB dalam menjalankan tugas tanggung jawabnya di PBF. Selain itu, semua SDM yang terlibat dalam 
penyaluran sediaan farmasi di PBF harus pernah mengikuti pelatihan $\mathrm{CDOB}$ agar proses dapat berjalan sesuai standar (Chandra et al., 2013). Kompetensi ini dapat didapatkan dengan mengikuti pelatihan. Pelatihan dapat dilakukan secara internal maupun eksternal. Pelatihan secara internal, narasumber dapat berasal dari pihak manajemen PBF atau APJ yang memiliki kompetensi CDOB (Wijaya \& Chan 2018).

Menurut penelitian Agustyani et al (2017) terdapat 12,2\% personalia PBF belum pernah mendapatkan CDOB, 19,51\% tidak memiliki catatan pernah melakukan atau mengikuti pelatihan, dan 43,9\% tidak melakukan pretest dan postest untuk mengevaluasi efektivitas pelatihan. Hasil penelitian dari Yusuf dan Avanti (2020) diketahui gambaran pelaksanaan pelatihan CDOB pada PBF sebagai berikut $46,7 \%$ selalu menyelenggarakan, 33,3\% sering, $16,7 \%$ jarang, dan 3,3\% tidak pernah. Kemudian penelitian dari Putra dan Hartini pada tahun 2012 diketahui hanya 48,3\% APJ PBF yang pernah mengikuti pelatihan CDOB. Berdasarkan tiga hasil penelitian tersebut dapat dilihat belum semua PBF memiliki personalia yang kompeten dibidang CDOB.

Pihak manajemen, APJ, dan semua personalia harus kompeten dalam CDOB agar dalam menjalankan operasional PBF memiliki kinerja sesuai dengan standar CDOB (Bhaskaran \& Venkatesh, 2019; Cvetanovski et al., 2020; Ferrario et al., 20I4). Personalia yang tidak memahami penanganan secara CDOB dapat menyebabkan penurunan mutu dan keamanan dari sediaan farmasi (Kumar \& Jha, 20I5). Cara lain untuk mengukur kapabilitas dan meningkatkan kinerja dari PBF adalah dengan melakukan audit terhadap proses CDOB (Bekčić et al., 2015; Ferrario et al., 2014; Tsvetanova, 2014). Pedagang besar farmasi yang rutin melakukan audit akan mendapatkan manfaat yang baik, karena proses CDOB yang dilakukan oleh personalia akan terevaluasi dan akan menghasilkan rekomendasi untuk perbaikan proses (Stoimenova et al., 2013).

B. Pengadaan
Fasilitas distribusi harus memperoleh pasokan obat dari pemasok yang mempunyai izin sesuai peraturan perundang-undangan. Sumber pengadaan PBF dapat berasal dari PBF pusat, PBF cabang, PBF lokal dan industri farmasi. Jika obat diperoleh dari PBF lain, maka PBF wajib memastikan bahwa pemasok tersebut telah mempunyai izin dan telah menerapkan prinsip dan pedoman CDOB. PBF wilayah Banjarmasin dan Banjarbaru memiliki perbedaan sumber pengadaan produk yaitu II PBF (36,7\%) memiliki sumber pengadaan dari PBF pusat, 5 PBF (16,6\%) memiliki sumber pengadaan dari industri farmasi, PBF pusat, PBF cabang, PBF lokal, dan I4 PBF lainnya (46,7\%) memiliki campuran dari beberapa sumber pengadaan tersebut (Yusuf \& Avanti, 2020). Berdasarkan data tersebut dapat diketahui bahwa PBF telah sesuai dengan ketentuan dari Peraturan Menteri Kesehatan Republik Indonesia Nomor 30 Tahun 2017 pasal 13 ayat 2 yang berbunyi PBF hanya dapat melaksanakan pengadaan obat dari industri farmasi dan atau sesama PBF (Permenkes RI, 2017).

Pedagang Besar Farmasi wajib melakukan pendokumentasian pengadaan, penyimpanan dan penyaluran sediaan farmasi secara tertib. Dua puluh delapan (97\%) PBF sudah melaksanakan dokumentasi. Jenis dokumentasi tentang penerimaan pesanan barang dari pelanggan dilakukan PBF baik secara manual maupun dengan komputer. Jenis dokumentasi lain yakni pemusnahan obat, pengembalian obat ke produsen, stok barang, pengurangan barang dari stok penjualan, pengiriman obat kepada pelanggan, pengeluaran dari gudang, penyimpanan obat, penerimaan dan pemesanan sediaan farmasi (Putra \& Hartini, 20/2). Prosedur pengadaan dan perilisan harus dikeluarkan secara resmi, guna memastikan bahwa produk farmasi yang akan didistribusikan bersumber dari pemasok yang legal (Mudin, 2018).

\section{Penyimpanan}

Penyusunan sediaan farmasi selama penyimpanan harus memperhatikan berdasarkan abjad, penggolongan obat, 
bentuk sediaan, serta Look Alike Sound Alike (LASA) (Sinen et al., 2017). Kondisi penyimpanan sediaan farmasi harus sesuai dengan penandaan yang didasarkan pada hasil pengujian stabilitas obat. Kondisi penyimpanan harus ditentukan dan dijelaskan pada label produk. Semua obat harus disimpan sesuai dengan kondisi yang dijelaskan pada label. Area penyimpanan harus dirancang atau disesuaikan untuk memastikan kondisi penyimpanan yang baik (Shafaat et al., 20l3). Ruang penyimpanan juga harus aman dari pencurian dan kebakaran (Sinen et al., 2017). Pengaturan suhu pada tempat penyimpanan dapat menggunakan sistem komputer yang otomatis, agar memudahkan kontrol suhu ruang penyimpanan (Chandra et al., 2013). Menurut hasil penelitian dari Yusuf dan Avanti (2020) diketahui bahwa PBF memiliki perbedaan jenis ruang penyimpanan produk yaitu I4 PBF (47\%) memiliki ruang penyimpanan hanya produk obat saja dan I6 PBF lainnya (53\%) memiliki ruang penyimpanan produk obat dan produk cold chain product. Semakin beragamnya item dan meningkatnya volume sediaan farmasi maka membutuhkan lebih banyak ruang penyimpanan (Sinen et al., 2017).

Pedagang besar farmasi merupakan tempat transit pertama dari sediaan farmasi setelah diproduksi oleh industri farmasi, sehingga selama sediaan farmasi berada di PBF kondisi penyimpanan sediaan farmasi sesuai dengan yang ketentuan dan dapat menjaga mutu obat tetap memenuhi persyaratan. Salah satu metode penyimpanan adalah First Expired First Out (FEFO) yang artinya obat yang memiliki kadaluwarsa lebih cepat yang dikeluarkan atau disalurkan terlebih dahulu. Penyimpanan dengan metode FEFO dapat mencegah kondisi obat menjadi rusak karena kadaluwarsa saat penyimpanan (Kristanti \& Ramadhania, 2020). Akibat dari adanya obat yang kadaluwarsa adalah PBF akan mengalami kerugian secara finansial karena ada sediaan farmasi yang tidak terjual serta PBF juga harus mengeluarkan biaya untuk melakukan pemusnahan.
Bangunan harus dirancang dan disesuaikan PBF untuk memastikan kondisi penyimpanan yang baik, keamanan yang memadai, kapasitas penyimpanan yang cukup, kondisi lingkungan yang terjamin, kebersihan, bebas dari hama, suhu ruangan, sirkulasi/ventilasi udara (Kristanti \& Ramadhania, 2020). Pada proses penyimpanan obat PBF harus mampu menjamin kualitas bangunan serta lingkungan area penyimpanan sesuai standar penyimpanan dari masing-masing sediaan farmasi. Pedagang besar farmasi sebagai perusahaan dan organisasi manajemen harus memiliki SOP untuk proses penyimpanan sediaan farmasi. Peran adanya SOP sangat penting karena dengan kepatuhan personalia dalam menerapkan SOP akan menjamin kualitas sediaan farmasi tetap berada dalam kualitas yang baik.

\section{Penyaluran}

Dalam penyaluran obat, setiap PBF dilarang melakukan praktek distribusi secara eceran dan melayani resep dokter. Pedagang besar farmasi hanya dapat menyalurkan obat kepada PBF lain, dan fasilitas pelayanan kefarmasian meliputi apotek, instalasi farmasi rumah sakit, puskesmas, klinik, atau toko obat (Agustyani et al., 2017). Pada umumnya penyaluran sediaan farmasi dari PBF menggunakan armada transportasi PBF sendiri ataupun menggunakan jasa pihak ketiga. Beberapa standar yang perlu diperhatikan dalam proses penyaluran atau pengiriman adalah kelayakan armada transportasi, tersedia tempat penyimpanan suhu tertentu, dan pengetahuan terhadap perlakukan khusus dari sediaan farmasi (Badurina et al., 2012; Sykes, 2018). Selama proses pengiriman standar kualitas dan mutu dari sediaan farmasi tidak boleh berubah ataupun berkurang. Oleh karena itu, personalia yang melakukan pengiriman sediaan farmasi harus memiliki pengetahuan yang baik (Cvetanovski et al., 2020).

\section{KESIMPULAN}

Cara distribusi obat yang baik harus diimplementasikan oleh semua PBF yang ada di Indonesia. Pedagang besar 
farmasi yang mengimplementasikan CDOB dengan baik akan memperoleh keuntungan dari sisi efisiensi operasional. Implementasi CDOB akan berjalan efektif ketika APJ dan semua personalia di PBF pernah mendapatkan pelatihan $\mathrm{CDOB}$.

\section{UCAPAN TERIMA KASIH}

Ucapan terima kasih diberikan kepada Universitas Sari Mulia yang telah memfasilitasi kegiatan penelitian ini.

\section{REFERENSI}

I. BPOM. 2020. Peraturan Badan Pengawas Obat Dan Makanan Nomor 6 Tahun 2020 Tentang Perubahan Atas Peraturan Badan Pengawas Obat Dan Makanan Nomor 9 Tahun 2019 Tentang Pedoman Teknis Cara Distribusi Obat Yang Baik. Jakarta.

2. Cvetanovski, F., Kocev, N., Tonic-Ribarska, J., and Trajkovic-Jolevska, S., 2020. Good Distribution Practice in preserving the integrity and safety of the supply chain of pharmaceuticals. Macedonian Pharmaceutical Bulletin, 66(03), 193-194. https://doi.org// 0.33320/maced.pharm.bull.2020.6 $\underline{6.03 .096}$

3. Jeong, S., and Ji, E., 2018. Global perspectives on ensuring the safety of pharmaceutical products in the distribution process. International Journal of Clinical Pharmacology and Therapeutics, 56(I), 12-23. https://doi.org//0.54|4/CP203/51

4. Chandra, A, A., Kim, B. M., Jeon, S. M., Rajeev, K. P., Shiu, K., Lee, S. I., ... and Lee, S. R., 20I3. Cold Storage monitoring of Pharmaceutical Products using Near Field Communication, ZigBee and Sensor Cloud. In Proceedings of the Korean Institute of Information and Commucation Sciences Conference (pp. 435-437). The Korea Institute of Information and Commucation Engineering.

5. Wijaya, M., Chan, A. 2018. Evaluasi Pelaksanaan Cara Distribusi Obat di PBF Rajawali Nusindo. Jurnal Farmasi Dunia, 2(3), 223-226.

6. Agustyani, V., Utami, W., Sumaryono, W., Athiyah, U., and Rahem, A., 2017. Evaluasi Penerapan CDOB sebagai Sistem Penjaminan Mutu pada Sejumlah PBF di Surabaya (Evaluation of CDOB Implementation as Quality Assurance System at PBF in Surabaya). Jurnal Ilmu Kefarmasian Indonesia, 15(I), 70-76.
7. Yusuf, B., \& Avanti, C. 2020. Cara Distribusi Obat yang Baik (CDOB) dan Implementasinya oleh Pedagang Besar Farmasi (PBF) di Kota BanjarmasinBanjarbaru Tahun 2019. Jurnal Pharmascience, 7(2), 58. https://doi.org// 0.20527/jps.v7i2.8992

8. Bhaskaran, I., and Venkatesh, M. P., 2019. Good Storage and Distribution practices for Pharmaceuticals in European Union. Journal of Pharmaceutical Sciences and Research, II(8), 29922997.

9. Kumar, N., and Jha, A. 2015. Quality Perspective of "Good Distribution Practices" in Indian Pharmaceutical Industry. IOSR Journal of Business and ManagementVer. I, I7(II), 23I9-7668. https://doi.org/10.9790/487X-17| I I2832

I0. Bekčić, S., Kelečević, N., Marinković, V., Tasić, L., and Krajnović, D., 20I5. Developing a quality management tool for preparing Good Distribution Practice audit of pharmaceutical contract vaccine distributor. Indian Journal of Pharmaceutical Education and Research, 49(3), 174-182. https://doi.org// 0.5530/ijper.49.3.2

II. Stoimenova, A., Savova, A., Manova, M., and Petrova, G., 2013. Quality management in pharmaceutical procurement: Most frequent nonconformities in pharmaceutical wholesalers in Bulgaria. Biotechnology and Biotechnological Equipment, 27(5), 4193-4196. https://doi.org// 0.5504/BBEQ.2013.0082

12. Permenkes RI. 2017. Peraturan Menteri Kesehatan Republik Indonesia Nomor 30 Tahun 2017 Tentang Perubahan Kedua Atas Peraturan Menteri Kesehatan Nomor I /48/Menkes/Per/Vi/20 I I Tentang Pedagang Besar Farmasi. Jakarta.

13. Putra, A. A. P., and Hartini, Y. S. 2012. Implementasi Cara Distribusi Obat Yang Baik Pada Pedagang Besar Farmasi Di Yogyakarta. Jurnal Farmasi Indonesia, 6(I), I48-54.

14. Mudin, N. 2018. Penjaminan Mutu dalam Pendistribusian Sediaan Farmasi. Farmasetika.Com (Online), 3(1), https://doi.org/10.24198/farmasetika.v3il.16793

I5. Sinen, Y., Lolo, W, A., and Supriati, H, S., 2017. Evaluasi Penyimpanan Dan Pendistribusian Obat Di Pt. Unggul laya Cipta Usaha Manado. PHARMACON, 6(3).

16. Shafaat, K., Hussain, A., Kumar, B., Rizwan UI Hasan, P. P., and Yadav, V. K., 20I3. An overview: 
storage of pharmaceutical products. World J Pharm Sci, 2(5), 2499-5I5.

17. Kristanti, M. W., and Ramadhania, Z. M., 2020. Evaluasi Kesesuaian Sistem Penyimpanan Obat, Suplemen, dan Kosmetik Eceran pada Salah Satu Gudang Pedagang Besar Farmasi (PBF) di Jakarta Pusat. Majalah Farmasetika, 5(2), 49. https://doi.org//0.24198/mfarmasetika.v5i2.26258

18. Badurina, G., Majić, Z., and Pavlin, S., 2012. Evaluation of Air Transportation Under Controlled Room Temperature for Pharmaceuticals. PROMET - Traffic\&Transportation, 23(2), 121-130. https://doi.org//0.7307/ptt.v23i2.139

19. Sykes, C. 2018. Time- and temperature-controlled transport: Supply chain challenges and solutions. $P$ and $T, 43(3), 154-157$.

20. Ferrario, A., Sautenkova, N., Bezverhni, Z., Seicas, R., Habicht, J., Kanavos, P., and Safta, V., 2014. An in-depth analysis of pharmaceutical regulation in the Republic of Moldova. Journal of Pharmaceutical Policy and Practice, 7(I), I-II. https://doi.org/10.1186/2052-321 I-7-4

21. Tsvetanova, Y. 2014. Features of internal audit in pharmaceutical industry. 30-34

22. Van Assche, K., Giralt, A. N., Caudron, J. M., Schiavetti, B., Pouget, C., Tsoumanis, A., Meessen, B., and Ravinetto, R., 2018. Pharmaceutical quality assurance of local private distributors: A secondary analysis in 13 low-income and middleincome countries. BMJ Global Health, 3(3), I-10. https://doi.org/ I0.1 I36/bmjgh-2018-00077| 